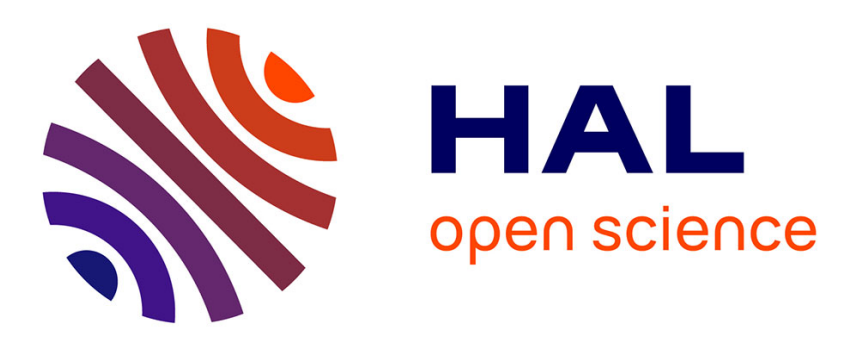

\title{
Elaboration and TEM structural study of interfaces in composites produced by precipitation
}

\author{
J. Du, A. Traverse, A. Peyrot, M. Backhaus-Ricoult, S. Hagège
}

\section{To cite this version:}

J. Du, A. Traverse, A. Peyrot, M. Backhaus-Ricoult, S. Hagège. Elaboration and TEM structural study of interfaces in composites produced by precipitation. European Conference on Advanced Materials and Processes 3 Conference Europeenne sur les Materiaux et les Procedes Avances 3, 1993, Paris, France. pp.C7-955-C7-960, 10.1051/jp4:19937147 . jpa-00251769

\section{HAL Id: jpa-00251769 https://hal.science/jpa-00251769}

Submitted on 1 Jan 1993

HAL is a multi-disciplinary open access archive for the deposit and dissemination of scientific research documents, whether they are published or not. The documents may come from teaching and research institutions in France or abroad, or from public or private research centers.
L'archive ouverte pluridisciplinaire HAL, est destinée au dépôt et à la diffusion de documents scientifiques de niveau recherche, publiés ou non, émanant des établissements d'enseignement et de recherche français ou étrangers, des laboratoires publics ou privés. 


\title{
Elaboration and TEM structural study of interfaces in composites produced by precipitation
}

\author{
J. DU* ${ }^{*}$ A. TRAVERSE ${ }^{* *}$, A. PEYROT ${ }^{* * * *}$, M. BACKHAUS-RICOULT ${ }^{* * *}$ and S. HAGĖGE* \\ ${ }^{*}$ CNRS-CECM, 94407 Vitry, France \\ ${ }^{* *}$ CNRS-CSNSM, 91405 Orsay, France \\ ${ }^{* * *}$ CNRS-LPM, 92195 Meudon, France
}

\begin{abstract}
Model ceramic matrix composites have been manufactured in a wide range of materials using the precipitation of a metal $\left(\mathrm{Cu}, \mathrm{Ni}, \mathrm{Cr}\right.$ ) in a ceramic matrix (nitride $\mathrm{AlN}$ or oxides $\mathrm{MgO}, \mathrm{Al}_{2} \mathrm{O}_{3}$ ) providing, in each case low energy configurations at the heterophase interfaces. In connection to microelectronic applications, copper metallic particles precipitate in AlN after implantation by copper ions and anneal of the ceramic matrix. Faceted particles are imaged by HRTEM and are associated to a low energy structural and chemical configuration. Internal reduction experiments have been carried out on $(\mathrm{Mg}, \mathrm{Ni}) \mathrm{O},(\mathrm{Mg}, \mathrm{Cu}) \mathrm{O}$ and ( $\mathrm{Al}, \mathrm{Cr}) 2 \mathrm{O} 3$ mixed oxides; the morphology, chemical composition and orientation relationship of the different precipitates are obtained through TEM observations and discussed in terms of interfacial energy and precipitate growth mechanism and kinetics. Conventional and high resolution TEM in conjonction to structural models have allowed a comprehensive description of the interface.
\end{abstract}

\section{Introduction}

In multiphase materials interfaces play an important role for the physical properties. For instance, the mechanical and thermal behaviour of a metal-ceramic composite depend on the microstructure of the interface and on the quality of the bonding between the phases. Therefore it is clear that a better understanding of the interfacial phenomenon based on the control of the bonding between the two components has to rely on a comprehensive structural and chemical analysis of the interface, i.e. the determination of the orientation relationship between the phases, the characterisation of the defects in the boundary, the analysis of the structure and the chemistry of the boundary and finally the study of the atomic relaxation across the interface. On a fundamental point of view the study of the atomic structure of such interfaces is clearly of an increasing interest : The two adjacent phases have a different crystallography, a different chemistry, a different electronic structure and they are bounded to each other with or without a good cohesion. The extension of all the theoretical models describing grain boundaries is therefore possible and already in progress for the most simple cases of heterophase interfaces. However the 
first necessary step for such a dual analysis, applied and fundamental, is the manufacturing of a low interfacial energy configuration, and this is only possible when for instance a small number of pertinent parameters have been selected and carefully monitored. This manufacturing imposes generally a home made elaboration in order to choose the most appropriate route and to control strictly every step of the process.

Table 1. General presentation of the systems studied and their field of interest.

\begin{tabular}{|c|c|c|}
\hline System & $\begin{array}{c}\mathbf{M}-\mathbf{A} \mathbf{1} \mathbf{N} \\
(\mathrm{M}=\mathrm{Cu}, \mathrm{Ti}, \mathrm{Fe})\end{array}$ & $\begin{array}{c}M-\mathbf{M} \mathbf{g O} \\
\mathbf{M}-\mathrm{AL}_{2} \mathrm{O}_{3} \\
(\mathrm{M}=\mathrm{Cu}, \mathrm{Ni}, \mathrm{Cr})\end{array}$ \\
\hline Application & hybrid micro-électronic & thermomec., electronic \\
\hline Scientific problem & $\begin{array}{l}\text { hex / fcc, hcp, bcc } \\
\text { chemical affinity } \\
\text { metal-ionocovalent }\end{array}$ & $\begin{array}{c}\mathrm{cub} / \mathrm{cub}, \text { rhomb/cub } \\
\text { thermodynamics } \\
\text { reduction path }\end{array}$ \\
\hline Elaboration & implantation & internal reduction \\
\hline $\begin{array}{c}\text { Analyses } \\
\text { Modelisation }\end{array}$ & $\begin{array}{c}\text { TEM, HRTEM } \\
\text { RBS, EXAFS }\end{array}$ & $\begin{array}{l}\text { TEM, HRTEM } \\
\text { EDX, SEM, }\end{array}$ \\
\hline
\end{tabular}

The results presented for this contribution are all rooted in progressing fields of applied research in materials science but they have been handled in order to provide some reliable information on the structure of interfaces at a fundamental level. Results on nitrides and oxides with their field of interest and scientific problems are summarised in table 1 . Their particular elaboration route is also indicated. Transmission electron microscopy is the major tool of characterisation but in each case complementary techniques have contributed to the general understanding of the structure of the interface.

\section{Ion implantation in a ceramic substrat (J. Du, A. Traverse and S. Hagège)}

Thanks to its good thermal conductivity aluminium nitride (AIN) is predicted to replace in a near future alumina as substrat for the micro-electronic industry. One of the main limiting factors for this application remains its metallisation. The sensitivity of AlN toward oxygen impurities makes the standard processes inapplicable. The non wettability of AlN by copper rules out thermocompression. It was therefore necessary to envisage a more sophisticated elaboration route in order to create and study the interface. 
$\mathrm{Cu}$-AlN metal-ceramic interfaces have been manufactured through copper ion implantation and annealing. This method has the main advantage of being impurity free and creates low energy configurations [1]. Moreover ion implantation and ion mixing are powerfull methods for creating and reinforcing heterophase interfaces.

Copper ions were implanted, at room temperature, on high purity AlN using the CSNSM facilities [2], $\left(E=100 \mathrm{KeV}\right.$, fluence $\left.=10^{17} \mathrm{ions} / \mathrm{cm}^{2}\right)$. The copper projected range has been calculated as $50 \mathrm{~nm}$ and the copper concentration over the implanted layer as $15 \%$ [3]. Post-annealing treatments were performed from 1073 to $1273 \mathrm{~K}$ and for 1 to 5 hours in vacuum $\left(<10^{-7}\right.$ Torr). Implantation and annealing have been monitored by RBS.

The nucleation of the copper precipitates is induced by the numerous faulted loops formed during ion implantation in the basal planes in the matrix and for the early stages of their growth the particles are severely constrained. These early stages are currently studied by EXAFS. Annealing ensures the growth of the precipitates and restaures partly the crystallinity of the matrix (Fig. 1). CTEM diffraction mode (Fig. 2.) shows an unique low energy orientation relationship for all the copper precipitates in the AlN matrix with:

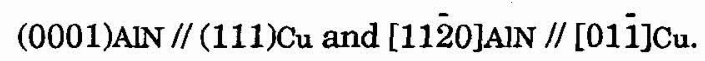

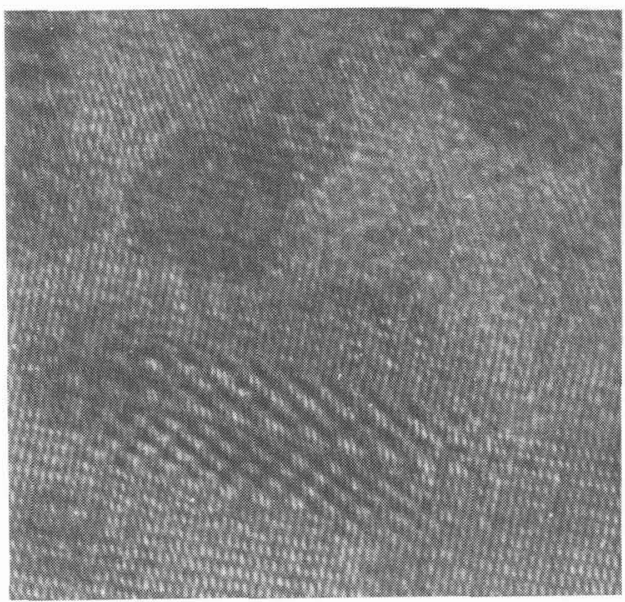

Figure 1. HREM micrograph of the precipitation of copper in aluminium nitride.

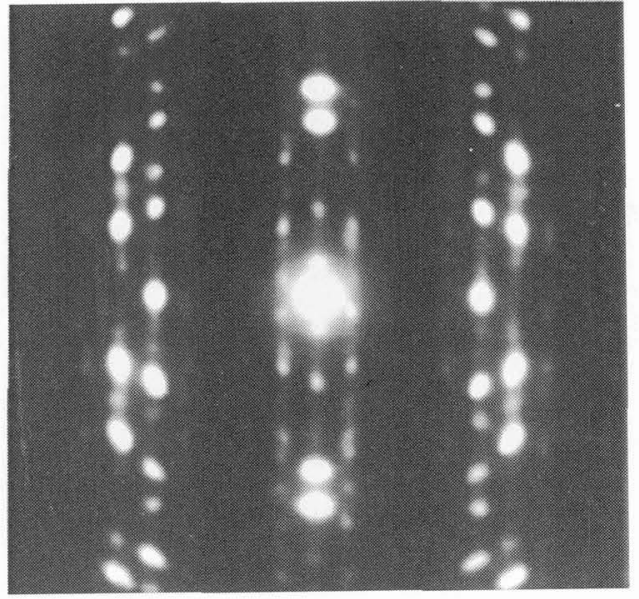

Figure 2. Diffraction pattern of copper and AIN demonstrating the unique orientation.

This orientation relationship corresponds to the parallelism of the densest planes and directions in the two structures and has been found in many other fcc-hcp systems [4,5].

The same procedure has been applied to the implantation of titanium and iron. In the case of titanium, preliminary results show that the metal has chemically reacted with the matrix forming a nitride. For iron it is intended to use Mössbauer spectroscopy to follow the very early stages of the nucleation and growth of the precipites. 


\section{Internal reduction of mixed oxides (A. Peyrot, M. Backhaus-Ricoult and S. Hagège)}

Particle reinforced composites produced by in-situ chemical reactions of fully dense single crystalline material exhibit very special properties which are related to the fact that the second phase forms by nucleation inside the solid matrix in a fully coherent manner. The conditions of nucleation and precipitate growth are strictly determined by thermodynamics, mechanical constraints and the mechanism of the chemical reaction. The partial reduction, under a low partial pressure of oxygen, of $\left(\mathrm{M}, \mathrm{M}^{\prime}\right)_{\mathrm{x}} \mathrm{O}$ single crystals leads to the precipitation of the more noble metal $\mathrm{M}^{\prime}$ in the ceramic matrix $\mathrm{MxOy}$ [6]. If the metals $\mathrm{M}, \mathrm{M}^{\prime}$ and the condition of reduction are correctly chosen according to the phase diagrams, the precipitation of $\mathrm{M}^{\prime}$ is fully coherent within the matrix; low energy interfaces are therefore produced and can be extensively studied by TEM. Metalceramic interfaces have been produced and analysed in the $(\mathrm{Mg}, \mathrm{Ni}) \mathrm{O},(\mathrm{Mg}, \mathrm{Cu}) \mathrm{O}$ and $(\mathrm{Al}, \mathrm{Cr}) 2 \mathrm{O} 3$ systems.

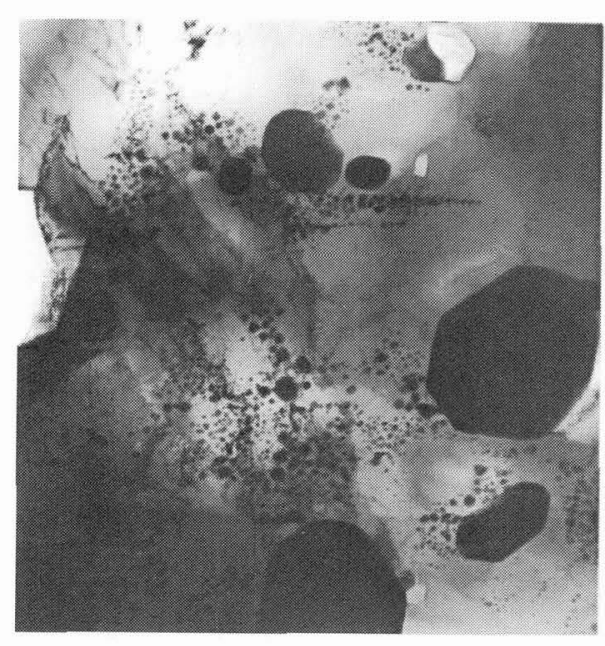

Figure 3. Precipitation of nickel in MgO.

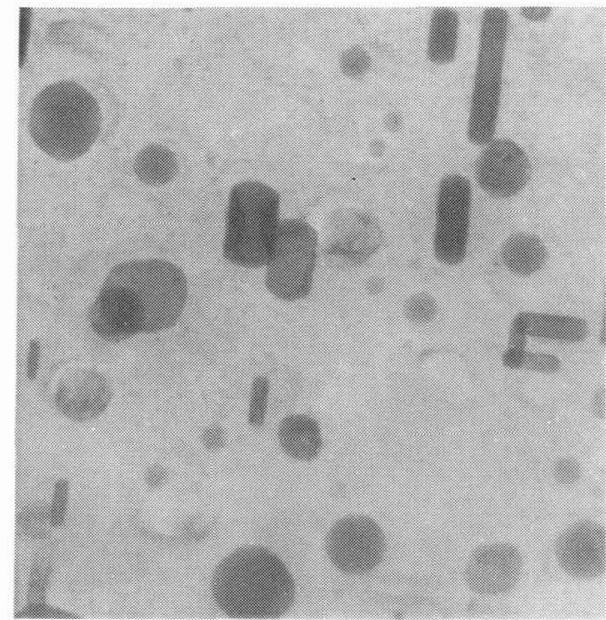

Figure 4. Precipitation of copper in $\mathrm{MgO}$.

The reduction of the mixed oxide $(\mathrm{Mg}, \mathrm{Ni}) \mathrm{O}$ has been carried out on single crystals containing 1,5 and $20 \%$ nickel at $1673 \mathrm{~K}$ in a $\mathrm{C} / \mathrm{CO}$ buffer followed by a rapid quenching [7]. In all the specimens the metal precipitates in a topotactical orientation (the so called cube on cube orientation with the axes of the cubic unit cells of nickel and $\mathrm{MgO}$ parallel to each other). This simple orientation occurs despite of the large misfit between the lattice parameters (16\%). Upon reduction a large number of dislocations is created and they act as diffusion pipes for the evacuation of the oxygen. At the metal- ceramic interface the misfit is accomodated by an array of dislocations $1.5 \mathrm{~nm}$ apart (Fig.3).

The precipitation scale obtained after internal reduction and quenching of 3\% copper $(\mathrm{Mg}, \mathrm{Cu}) \mathrm{O}$ single crystals at $1273 \mathrm{~K}$ in a $\mathrm{C} / \mathrm{CO}$ buffer reveals a number of special 
orientation relationships between the metal copper and the ceramic matrix $\mathrm{MgO}$. The intermediate valence state of copper induces a mechanism in two steps. First cuprite, $\mathrm{Cu} 20$, precipitates within a limited number of orientations and then as the reaction front penetrates further into the matrix, cuprite particles are reduced to metallic copper [8]. The orientation of the particles within the matrix is only maintained in the case of the cube-on-cube orientation while it evolves into a low energy twinned orientation for the other ones (Fig. 4). The twinned orientation reads as:

(001)MgO // (112) Cu and [010]MgO // [111]Cu

$(\mathrm{Al}, \mathrm{Cr}) 2 \mathrm{O} 3$ single crystals and polycrystals with a chromium content ranging from 0.5 to $10 \%$ were internally reduced between 1673 and $1970 \mathrm{~K}$ in an $\mathrm{Al} / \mathrm{Al} 2 \mathrm{O} 3$ buffer. As a result two types of discrete metallic precipitates developped in the bulk of the matrix. Each type of precipitates is characterized by a particular morphology (needle or spheroid) and a particular orientation relationship within the matrix [9]. The length of the first type of precipitates may vary from $100 \mathrm{~nm}$ to $1.5 \mu \mathrm{m}$, their section is always of a few $\mathrm{nm}$ wide. The spheroidal precipitates are more frequent but smaller in size ranging from 10 to $40 \mathrm{~nm}$, their shape is roughly the one of a flattened sphere (Fig. 6).

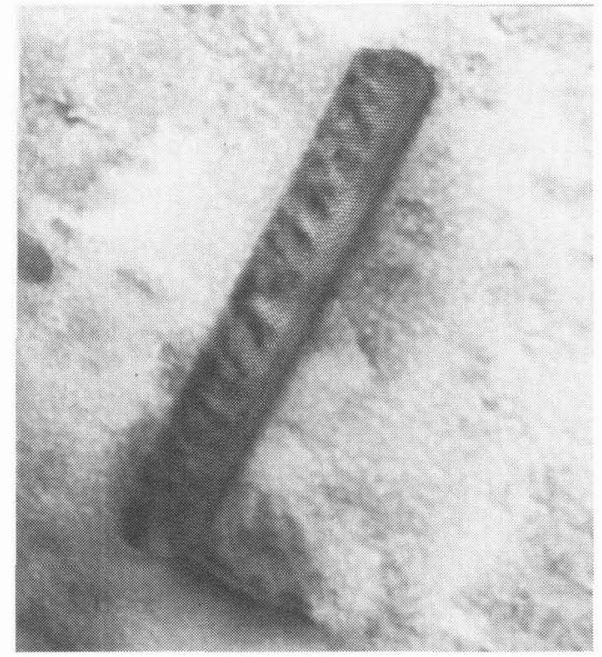

Figure 5. Cr needle-like precipitates in alumina

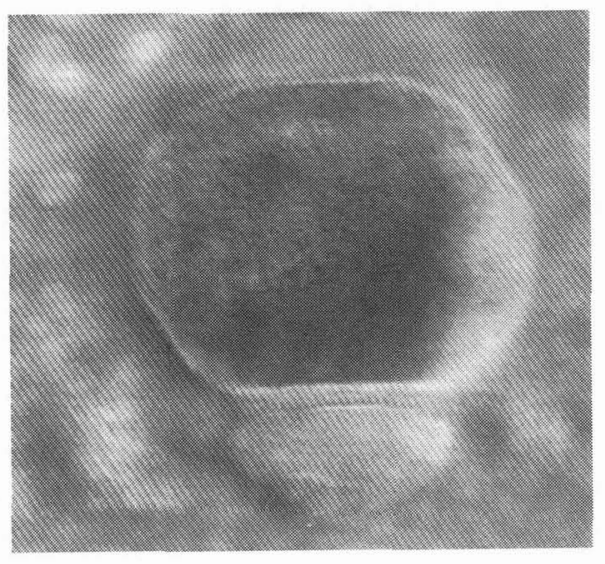

Figure 6. Cr spheroidal precipitates in alumina

The needle shaped precipitates have their elongated faces parallel to the common prismatic planes of their orientation which reads as

$$
\text { (0001)Al2O3 // (111)Cr and [112̄0]Al2O3 // [011] Cr. }
$$

The direction of elongation of the needle is the common three fold axis of the two structures. The stability of these precipitates is attributed to the parallelism of the rather 
dense planes of both structure and a good fit of the two lattice parameters when considering a supercell.

The smallest precipitates are found in a narrow range of orientations within the matrix. They have all in common the parallelism of the densest planes of both structures :

$$
\text { (0001)Al203 // (011)Cr. }
$$

These small precipitates are always faceted along several of the densest planes of alumina i.e. $(1 \overline{1} \overline{2}),(01 \overline{1} 2)$, the flatened section of the precipitate, the largest facet, is parallel to the common densest planes of the two structures. Their morphology is therefore dictated by the parallelism of these densest planes whereas their small size may be the result of the rather bad fit between the the two lattice parameters for this orientation.

\section{Conclusions}

For both ion implantation and internal reduction low energy orientation relationships between the precipitates and the matrix have been found in our specimens. These results demonstrate that metal reinforced ceramic composites having very special properties can be manufactured by these elaboration routes. Their special properties are related to the special conditions under which the elaboration has been carried out and can adapted to any particular application by modifying accordingly the parameters of the elaboration. On a fundamental point of view these orientation relationships are very close to each other whatever the system studied and can be seen as a firm basis for the extension of grain boundary modeling to interphase interface modeling. The orientation of the precipitates in the matrix are essentially based on the parallelism of the densest planes of each structure whereas the morphology of the composite depends more directly on the precipitation mechanism and on the registry of the lattice parameters.

\section{References}

1. Du J., Traverse A. and Hagège S., in "Intergranular and Interphase Boundaries in Materials iib92", Trans Tech Pub., Materials Science Forum, Vol. 126-128, 703.

2. Cottereau E., J. Camplan J. , Chaumont J. and Meunier R.: Mat. Sci. Eng., 1989, B2, 217.

3. Ziegler J.F., Biersade J.P. and Littmark U.: "The Stopping and Range of Ions in Solids", 1986, Vol. I and II, (PergamonPress, New York).

4. G. Regheere G. and J.M. Penisson J.M. : J. de Phys., 1990, C1-51, 909.

5. Howe H., Dahmen U. and Gronsky R.: Phil. Mag. A, 1987, 56, 31

6. Schmalzried H. (1884) Ber. Bunsenges. Phys. Chem. 88, 1186

7. Backhaus-Ricoult M., Ricoult D. (1988) J.Mat Sci 23, 1309

8. Backhaus-Ricoult M., Hagège S. (1992) Acta Met Mat, 40, S267-74

9. Backhaus-Ricoult M., Hagège S., Peyrot A. and Moreau P. (1993) J. Am. Ceram. Soc to appear. 